\title{
Comparative study between hemodialysis and hemodiafiltration regarding effect on cognitive function
}

\section{Amr Ahmed Mahmoud Sayed, Ahmed Mohamed Tawfik, Essam Nour El-Din Afify, Khaled Hussien Hassan Abou Seif.}

Internal Medicine and Nephrology, Faculty of Medicine, Ain Shams University

Corresponding author: Amr Ahmed Mahmoud Sayed, Mobile: +20101071612; E mail: amrhikal62@ gmail.com

\begin{abstract}
Objective: Cognitive impairment $(\mathrm{CI})$ is very common in chronic kidney disease (CKD) and is strongly associated with increased mortality. Hemodiafiltration (HDF) is a dialysis modality that is thought to offer better clearance of middle molecules, more stability of intradialytic blood pressure and better cognitive state of end stage renal disease (ESRD) patients. So, we aim to compare cognitive function in hemodialysis (HD) versus HDF patients. Materials and

than MMSE. CI is often under-diagnosed due to the patients' unawareness of their cognitive deficits. Therefore, screening tests would be more appropriate for these patients. The MoCA test which is sensitive to executive dysfunction seems to be more adaptable to assess CI in both groups of this study; HD patients and HDF patients; HDF is a modality of dialysis with better outcome regarding cognitive function in ESRD patients.
\end{abstract} Methods: In a cross sectional study, 100 patients were divided as: 50 patients maintained on HD 3 regular sessions per week, 50 patients maintained on 3 regular sessions of HDF per week. Patients with dementia or delirium, Patients with psychosis or bipolar disorder, Patients who are under the influence of a substance or alcohol, Patients with previous history of cerebrovascular stroke were excluded. History including demographic data, etiology of ESRD and comorbidities was taken. Cognitive assessment was done using Mini-mental state examination (MMSE) and Montreal cognitive assessment (MoCA). Blood samples were taken to measure kidney function tests, metabolic profile, complete blood count, thyroid and parathyroid function tests.

Results Cognitive assessment using MoCA showed that in HD group: 12 patients were found to have $\mathrm{CI}$ and 38 patients were normal, while in HDF group only 4 patients were found to have $\mathrm{CI}$ and the other 46 patients had normal cognitive function. Conclusions Our study shows that the MoCA test is a valid screening test for CI in both HD patients and HDF patients. It demonstrated higher sensitivity for screening patients with mild CI

Key Words: HD, HDF, CI, MoCA, MMSE.

\section{INTRODUCTION}

In young and middle aged ESRD patients, the prevalence of $\mathrm{CI}$ ranges from $10 \%$ to $30 \%$, rising to $30 \%$ to $55 \%$ in patients older than 75years (Kurella et al., 2010). Because HD is an intermittent treatment, fluid and uremic toxins often have to be removed at quite a high rate. This exposes HD patients to intradialytic hypotension (IDH) and rapid osmotic changes. IDH is associated with attention and executive function deficits (Costa et al., 2014). HDF has been postulated to improve removal of middle molecular weight uremic toxins, reduce IDH, and reduce dialysis-related pathology, such as amyloidosis and accelerated atherosclerosis (Canaud et al., 2018). Advanced age, lower 
education, and depression were also correlated with deterioration in general and specific cognitive function. After multivariable adjustment, both global and specific $\mathrm{CI}$ at baseline were associated with a greater rate of hospitalization, and memory dysfunction was associated with a lower dialysis modality survival rate (Zhang et al., 2018). Although patients on dialysis have traditional and ESRD-specific risk factors for $\mathrm{CI}$, it is crucial to evaluate the role of the HD process itself in contributing to cognitive decline (Wolfgram, 2018). Dialysis is a state of chronic inflammation resulting from exogenous factors such as HD membranes and central venous catheters, cellular factors such as oxidative stress, tissue factors such as hypoxia, salt and fluid overload, microbial factors such as immune dysfunction, and from retention of uremic toxins (Cobo et al., 2018). Since dialysis induces oxidative stress and chronic inflammation, it could be hypothesized that the pro-inflammatory effects of dialysis could also have a negative effect on brain amyloid deposition (Heneka et al., 2015). There are limited data and few longitudinal studies comparing cognitive function in patients with respect to different dialysis modalities. Also, more recent work also reports that cognition (specifically MoCA executive scores) declines faster in HD patients than in peritoneal dialysis ones (Iyasere et al., 2017). HDF is a dialysis modality that is associated with better hemodynamic stability. A meta-analysis, using the individual patient data from four RCTs, showed better survival in HDF vs. HD patients. The largest benefit was found when a convection volume of $>23 \mathrm{~L} / \mathrm{session}$ (highvolume) was achieved. The mechanism of the beneficial effect is still unknown, but may be due to superior hemodynamic tolerance with a lower incidence of IDH and a better preservation of the cardiac and cerebrovascular integrity, improved hemodynamic stability with high-volume HDF vs. HD treatment results in better preservation of cerebral perfusion, potentially setting a limit to the accelerated cognitive decline and progression of white matter lesions in ESRD patients (Kim, 2018). The A $\beta$ s removal efficiencies were improved by $\mathrm{HDF}$, which enhanced the adsorption of $\mathrm{A} \beta \mathrm{s}$ on micro pores of hollow fibers. Further, HDF increased $A \beta s$ influx into the blood, which might be triggered by the change of blood A $\beta$ s concentration (Morikawa et al., 2016). Although both a better hemodynamic profile and an improvement of the uremic environment may contribute to the beneficial effects of HDF on clinical outcome, the exact mechanisms are still unclear (Den Hoedt et al., 2014). In recent years, however, the frequency of testing has decreased considerably and disposables became cheaper. Therefore, it is hardly surprising that more recent evaluations showed that the costs of HDF are comparable to high-flux HD or even lower (Lebourg et al., 2013). 


\section{AIM OF THE STUDY}

The aim of this study was to compare between hemodialysis and hemodiafiltration regarding effect on cognitive function.

\section{PATIENTS AND METHODS}

Type of study: Cross sectional study. Study setting: Dialysis units in both Ain Shams University hospitals and Air Forces Military hospital.

Study period: 6 months (from September 2018 to March 2019)

Study population: One hundred patients were divided as 50 ESRD patients on maintenance hemodialysis; 3 regular sessions per week in Ain Shams University hemodialysis units and 50 ESRD patients on 3 regular sessions of HDF per week in Air Forces Military hospital.

\section{Inclusion criteria:}

Patients included were 18 years old or more.

\section{Exclusion criteria:}

$>$ Patients with dementia or delirium.

$>$ Patients with psychosis or bipolar disorder.

$>$ Patients who are under the influence of a substance or alcohol.

$>$ Patients with previous history of cerebrovascular stroke.

\section{Ethical Considerations:}

- Informed written consent was taken before recruitment in the study after explaining the purpose and procedures of the study.

- The privacy of participants and confidentiality of data was guaranteed during the various phases of the study.

\section{Study procedures:}

1. Complete history taking including patient baseline demographic data as age, gender, body size, co-morbidities (Diabetes mellitus, hypertension, hyperlipidemia, tobacco use, cerebrovascular disease, and pulmonary disease).
2. Full physical examination

3. Laboratory data at the initiation of dialysis including (Complete blood count, S.creatinine, blood urea, sodium, potassium, serum calcium, serum phosphorus and serum uric acid).

4. Parathyroid hormone, Iron study.

5. Thyroid function tests.

6. Calculated $\mathrm{Kt} / \mathrm{V}$ using $\mathrm{Kt} / \mathrm{V}$ Daugirdas Formula: Kt/V Daugirdas $=-\ln (($ BUNPost $/$ BUNPre $)-(0.008 *$ Hours $))+((4-(3.5 *$ BUNPost / BUNPre)) * UFVol / WeightPost). 7. MoCA (Nasreddine et al., 2005), Arabic version (Abdel Rahman and El Gaafary, 2009).

8. MMSE (Folstein et al., 1975), Arabic version (El-Okl et al., 2002).

\section{Statistical Analysis Method}

- The results were statically analyzed and correlated in relation to demographic data and treatment.

\section{RESULTS}

Patients were divided into 2 groups: 1st group: 50 patients of them in ElDemerdash Hospital hemodialysis unit maintained on low flux HD. 2nd group: 50 patients in Air Forces Military Hospital hemodialysis unit maintained on HDF. Their ages ranged from 21 to 75 years. No significant differences were found between both groups regarding age and comorbidities.

Cognitive assessment using MoCA showed that in HD group: 12 patients (24\%) were found to have CI and 38 patients (76\%) were normal, while in HDF group only 4 patients (8\%) were found to have CI and the other 46 patients $(92 \%)$ were normal with significant 
statistical difference between the 2 groups with (P value 0.029).

By using MMSE, although that only 2 patients (4\%) in HD group were found to have $\mathrm{CI}$, the other 48 patients $(96 \%)$ were normal and no patients were found to have CI in HDF group, but patient's values ranges from 22 to 30 degrees in HD group with mean range $27.96 \pm 1.77$ and ranges from 26 to 30 degrees in HDF group with mean range 28.92 \pm 0.99 with highly significant statistical difference between the 2 groups with (P value 0.001).

There were significant positive correlation between serum iron with both tests; MoCA with $\mathrm{P}$ value (0.007) and MMSE with $\mathrm{P}$ value (0.037), significant positive correlation between serum ferritin and MMSE with $\mathrm{P}$ value (0.023) and significant positive correlation between Tsat with both tests; MoCA with $\mathrm{P}$ value (0.007) and MMSE with $\mathrm{P}$ value (0.006). There was a significant negative correlation between TIBC and MMSE with $\mathrm{P}$ value (0.044). Also, there was a significant negative correlation between KT/V and patients' scores by MMSE with $\mathrm{P}$ value (0.049).

In HD group, patients' scores by Minimental scale had a significant negative correlation with both $\mathrm{KT} / \mathrm{V}$ with (P value $\mathbf{0 . 0 4 7}$ ) and TIBC (P value 0.039). Also in this group, patients' scores by MMSE had a significant positive correlation with serum $\mathrm{Na}$ levels (p value 0.022 ).
In HDF group, patients' scores by MoCA had a statistically significant negative correlation with age of the patients with (P value $\mathbf{0 . 0 2 8})$.

Table (1) Cognitive assessment using Montreal cognitive assessment, Minimental state examination in both groups:

\begin{tabular}{|c|c|c|c|c|c|}
\hline & $\begin{array}{l}\text { Hemod } \\
\text { ialysis } \\
\text { group }\end{array}$ & $\begin{array}{l}\text { HDF } \\
\text { group }\end{array}$ & \multirow{2}{*}{$\begin{array}{c}\text { Test } \\
\text { value }\end{array}$} & \multirow{2}{*}{$\begin{array}{c}\text { P- } \\
\text { valu } \\
\text { e }\end{array}$} \\
\hline & & $\begin{array}{c}\text { No. }= \\
50\end{array}$ & $\begin{array}{c}\text { No. }= \\
50\end{array}$ & & \\
\hline \multirow{2}{*}{$\begin{array}{l}\text { Montreal } \\
\text { cognitive } \\
\text { assessment }\end{array}$} & $\begin{array}{l}\text { Mean } \pm \text { SD } \\
\text { Range }\end{array}$ & $\begin{array}{c}27.04 \pm \\
1.85 \\
23-30\end{array}$ & $\begin{array}{c}27.48 \\
\pm 1.53 \\
23- \\
30\end{array}$ & $\begin{array}{c}- \\
1.296 \\
\bullet\end{array}$ & $\begin{array}{c}0.19 \\
8\end{array}$ \\
\hline & $\begin{array}{l}\text { Normal } \\
\text { Cognitive } \\
\text { impairment }\end{array}$ & $\begin{array}{c}38 \\
(76.0 \%) \\
\\
12 \\
(24.0 \%)\end{array}$ & $\begin{array}{c}46 \\
(92.0 \\
\%) \\
4 \\
(8.0 \%)\end{array}$ & $\begin{array}{c}4.762 \\
*\end{array}$ & $\begin{array}{l}0.0 \\
29\end{array}$ \\
\hline \multirow{2}{*}{$\begin{array}{l}\text { Miniment } \\
\text { al state } \\
\text { examinati } \\
\text { on }\end{array}$} & $\begin{array}{l}\text { Mean } \pm \text { SD } \\
\text { Range }\end{array}$ & $\begin{array}{c}27.96 \pm \\
1.77 \\
22-30\end{array}$ & $\begin{array}{c}28.92 \\
\pm 0.99 \\
26- \\
30\end{array}$ & $\begin{array}{c}- \\
3.347 \\
\bullet\end{array}$ & $\begin{array}{c}0.0 \\
01\end{array}$ \\
\hline & $\begin{array}{l}\text { Normal } \\
\text { Cognitive } \\
\text { impairment }\end{array}$ & $\begin{array}{c}48 \\
(96.0 \%) \\
\\
2 \\
(4.0 \%)\end{array}$ & $\begin{array}{c}50 \\
(100.0 \\
\%) \\
0 \\
(0.0 \%)\end{array}$ & $\begin{array}{c}2.041 \\
*\end{array}$ & $\begin{array}{c}0.15 \\
3\end{array}$ \\
\hline
\end{tabular}

P-value > 0.05: Non significant; P-value < 0.05:

Significant; P-value < 0.01: Highly significant

*: Chi-square test; $\bullet$ : Independent t-test. 
Table (2) Correlation of Montreal cognitive assessment and Minimental scale with the other parameters in all cases:

\begin{tabular}{|c|c|c|c|c|}
\hline & \multicolumn{4}{|c|}{ All cases } \\
\hline & \multicolumn{2}{|c|}{$\begin{array}{c}\text { Montreal cognitive } \\
\text { assessment }\end{array}$} & \multicolumn{2}{|c|}{$\begin{array}{c}\text { Minimental } \\
\text { scale }\end{array}$} \\
\hline & $\mathbf{r}$ & P-value & $\mathbf{r}$ & P-value \\
\hline Age & -0.131 & 0.196 & -0.030 & 0.767 \\
\hline $\begin{array}{c}\text { Duration on } \\
\text { HDx } \\
\end{array}$ & -0.113 & 0.264 & -0.013 & 0.900 \\
\hline Weight & -0.090 & 0.376 & -0.084 & 0.406 \\
\hline Pre BUN & 0.041 & 0.686 & 0.085 & 0.399 \\
\hline Post BUN & -0.006 & 0.951 & -0.156 & 0.121 \\
\hline KT/V & 0.071 & 0.484 & $\begin{array}{c}- \\
0.197 * \\
\end{array}$ & 0.049 \\
\hline PTH & 0.006 & 0.949 & 0.004 & 0.967 \\
\hline HGB level & -0.033 & 0.745 & 0.035 & 0.729 \\
\hline Seum Iron & $0.268 * *$ & 0.007 & $0.209^{*}$ & 0.037 \\
\hline Ferritin & 0.126 & 0.211 & $0.227^{*}$ & 0.023 \\
\hline TIBC & -0.056 & 0.581 & $\begin{array}{c}- \\
0.201^{*}\end{array}$ & 0.044 \\
\hline Tsat & $0.267 * *$ & 0.007 & $\begin{array}{c}0.275^{*} \\
*\end{array}$ & 0.006 \\
\hline $\begin{array}{c}\text { Serum } \\
\text { creatinine }\end{array}$ & 0.130 & 0.198 & 0.112 & 0.269 \\
\hline $\mathrm{Na}$ & 0.017 & 0.863 & 0.121 & 0.231 \\
\hline $\mathbf{K}$ & 0.123 & 0.222 & 0.079 & 0.435 \\
\hline $\mathrm{Ca}$ & 0.000 & 0.997 & 0.115 & 0.256 \\
\hline PO4 & 0.038 & 0.706 & -0.137 & 0.175 \\
\hline Uric acid & -0.069 & 0.497 & 0.001 & 0.992 \\
\hline Albumin & 0.001 & 0.995 & 0.107 & 0.290 \\
\hline Free T4 & -0.024 & 0.811 & -0.067 & 0.508 \\
\hline Free T3 & -0.067 & 0.506 & -0.101 & 0.319 \\
\hline TSH & -0.099 & 0.329 & -0.009 & 0.928 \\
\hline
\end{tabular}

Table (3) Correlation of Montreal cognitive assessment and Minimental scale with the other parameters in hemodialysis group:

\begin{tabular}{|c|c|c|c|c|}
\hline \multirow{2}{*}{} & \multicolumn{4}{|c|}{ Hemodialysis group } \\
\cline { 2 - 5 } & \multicolumn{2}{|c|}{$\begin{array}{c}\text { Montreal cognitive } \\
\text { assessment }\end{array}$} & \multicolumn{2}{c|}{$\begin{array}{c}\text { Minimental } \\
\text { scale }\end{array}$} \\
\cline { 2 - 5 } & $\mathbf{r}$ & P-value & r & P-value \\
\hline Age & 0.004 & 0.978 & 0.104 & 0.473 \\
\hline Duration on HD & -0.104 & 0.472 & -0.047 & 0.748 \\
\hline Weight & -0.005 & 0.971 & -0.182 & 0.205 \\
\hline Pre BUN & 0.062 & 0.667 & 0.196 & 0.173 \\
\hline Post BUN & 0.076 & 0.602 & -0.072 & 0.618 \\
\hline KT/V & 0.128 & 0.374 & - & $\mathbf{0 . 0 4 7}$ \\
\hline PTH & 0.008 & 0.957 & -0.090 & 0.534 \\
\hline HGB level & -0.002 & 0.991 & 0.126 & 0.384 \\
\hline Seum Iron & 0.258 & 0.070 & 0.127 & 0.380 \\
\hline Ferritin & 0.004 & 0.976 & 0.184 & 0.201 \\
\hline
\end{tabular}

\begin{tabular}{|c|c|c|c|c|}
\hline TIBC & -0.037 & 0.800 & $\begin{array}{c}- \\
0.292^{*}\end{array}$ & $\mathbf{0 . 0 3 9}$ \\
\hline Tsat & 0.272 & 0.056 & 0.229 & 0.109 \\
\hline $\begin{array}{c}\text { Serum } \\
\text { creatinine }\end{array}$ & 0.178 & 0.217 & 0.141 & 0.329 \\
\hline $\mathrm{Na}$ & 0.145 & 0.314 & $0.323 *$ & $\mathbf{0 . 0 2 2}$ \\
\hline $\mathrm{K}$ & -0.013 & 0.927 & 0.007 & 0.964 \\
\hline $\mathrm{Ca}$ & -0.007 & 0.963 & 0.258 & 0.070 \\
\hline PO4 & -0.014 & 0.923 & -0.258 & 0.071 \\
\hline Uric acid & -0.257 & 0.072 & -0.052 & 0.722 \\
\hline Albumin & 0.020 & 0.888 & 0.173 & 0.229 \\
\hline Free T4 & -0.140 & 0.332 & -0.172 & 0.232 \\
\hline Free T3 & 0.007 & 0.962 & 0.120 & 0.406 \\
\hline TSH & -0.140 & 0.334 & -0.079 & 0.583 \\
\hline
\end{tabular}

Table (4) Correlation of Montreal cognitive assessment and Minimental scale with the other parameters in HDF group:

\begin{tabular}{|c|c|c|c|c|}
\hline & \multicolumn{4}{|c|}{ HDF group } \\
\hline & \multicolumn{2}{|c|}{$\begin{array}{c}\text { Montreal cognitive } \\
\text { assessment }\end{array}$} & \multicolumn{2}{|c|}{\begin{tabular}{|c|}
$\begin{array}{c}\text { Minimental } \\
\text { scale }\end{array}$ \\
\end{tabular}} \\
\hline & $\mathbf{r}$ & P-value & $\mathbf{r}$ & $\begin{array}{c}\text { P- } \\
\text { value }\end{array}$ \\
\hline Age & $-0.311 *$ & 0.028 & $\begin{array}{c}- \\
0.247\end{array}$ & 0.083 \\
\hline $\begin{array}{c}\text { Duration on } \\
\text { HD } \\
\end{array}$ & -0.137 & 0.343 & $\begin{array}{c}- \\
0.035 \\
\end{array}$ & 0.807 \\
\hline Weight & -0.219 & 0.126 & $\begin{array}{c}- \\
0.066 \\
\end{array}$ & 0.649 \\
\hline Pre BUN & 0.023 & 0.875 & 0.058 & 0.69 \\
\hline Post BUN & -0.117 & 0.42 & $\begin{array}{c}- \\
0.199 \\
\end{array}$ & 0.166 \\
\hline $\mathrm{KT} / \mathrm{V}$ & -0.025 & 0.865 & $\begin{array}{c}- \\
0.161\end{array}$ & 0.263 \\
\hline PTH & 0.042 & 0.771 & 0.152 & 0.292 \\
\hline HGB level & -0.088 & 0.542 & $\begin{array}{c}- \\
0.113\end{array}$ & 0.436 \\
\hline Serum Iron & 0.256 & 0.073 & 0.227 & 0.113 \\
\hline Ferritin & 0.251 & 0.079 & 0.276 & 0.052 \\
\hline TIBC & -0.055 & 0.707 & \begin{tabular}{|l|}
-0.17 \\
\end{tabular} & 0.237 \\
\hline Tsat & 0.243 & 0.089 & 0.267 & 0.061 \\
\hline $\begin{array}{c}\text { Serum } \\
\text { creatinine }\end{array}$ & 0.138 & 0.34 & 0.166 & 0.25 \\
\hline $\mathrm{Na}$ & -0.129 & 0.373 & -0.1 & 0.488 \\
\hline $\mathrm{K}$ & 0.252 & 0.077 & 0.106 & 0.464 \\
\hline $\mathrm{Ca}$ & -0.017 & 0.907 & $\begin{array}{c}- \\
0.118 \\
\end{array}$ & 0.415 \\
\hline $\mathrm{PO} 4$ & 0.085 & 0.555 & $\begin{array}{c}- \\
0.023 \\
\end{array}$ & 0.875 \\
\hline Uric acid & 0.187 & 0.193 & 0.079 & 0.584 \\
\hline Albumin & -0.038 & 0.794 & 0.057 & 0.694 \\
\hline Free $\mathrm{T} 4$ & 0.104 & 0.473 & \begin{tabular}{|l|}
0.029 \\
\end{tabular} & 0.844 \\
\hline Free T3 & -0.123 & 0.396 & $\begin{array}{c}- \\
0.241 \\
\end{array}$ & 0.092 \\
\hline TSH & -0.136 & 0.346 & $\begin{array}{c}- \\
0.096 \\
\end{array}$ & 0.507 \\
\hline
\end{tabular}




\section{DISCUSSION}

The present study was conducted upon 100 patients: 50 patients of them maintained on low flux $\mathrm{HD}$, the other 50 patients maintained on HDF (43 males, 57 females; Their ages ranged from 21 to 75 years) in order to compare cognitive function in HD vs HDF patients.

HD patients were divided according to etiology of ESRD into: 15 patients with obstructive uropathy (30\%), 12 hypertensive patients (24\%), 12 patients with chronic glomerulonephritis (24\%), 6 patients with DM (12\%) and 5 patients with amyloidosis (10\%). While in HDF group, patients were divided according to etiology of ESRD into: 15 patients with obstructive uropathy (30\%), 10 hypertensive patients (20\%), 12 patients with chronic glomerulonephritis (24\%), 8 patients with DM (16\%) and 5 patients with amyloidosis (10\%) with no significant difference between the 2 groups.

Cognitive assessment using MoCA in HD group revealed: 12 patients (24\%) were found to have CI and 38 patients (76\%) were normal, while in HDF group only 4 patients (8\%) were found to have CI and the other 46 patients $(92 \%)$ were normal with significant difference between the 2 groups with ( $\mathrm{P}$ value 0.029) and this is the main finding in our study.

By using MMSE, although that only 2 patients (4\%) in HD group were found to have CI, the other 48 patients $(96 \%)$ were normal and no patients were found to have CI in HDF group, but patient's values ranges from 22 to 30 degrees in HD group with mean range $27.96 \pm 1.77$ and ranges from 26 to 30 degrees in HDF group with mean range 28.92 \pm 0.99 with highly significant difference between the 2 groups with (P value 0.001 ). So in our study, MoCA test demonstrated high sensitivity for screening patients with CI. Studies found that many patients receive lower scores on the MoCA than the MMSE when they are combined because executive functions are not assessed in MMSE and MoCA test has more detailed assessment of all cognitive domains (Nasreddine et al., 2005).

Poor performance suggested that deficits in the executive function were also prominent in the HD group. Patients with kidney disease seemed to have particular difficulties in frontal lobe or executive dysfunction. To check the patterns of cognitive deficit in specific domains may help the clinician's treatment plan in terms of conversion to dementia and types of dementia likely to be encountered (Lee et al., 2018).

In our study, serum iron levels significantly correlated with MoCA and MMSE scores in all study population with $\mathrm{P}$ value 0.007 and 0.037 respectively. Also TSAT significantly correlated with both MoCA and MMSE scores with $\mathrm{P}$ value 0.007 and 0.006 respectively. 
As Murray et al suggested that the best time to assess the cognitive abilities is on the day after dialysis or immediately before the dialysis session, we tested our patients 12 hours before the dialysis session to avoid post-dialysis fatigue, hypotension and other complications that may affect attention and recall results (Murray et al., 2007).

\section{Conclusion}

The MoCA test is a valid screening test for CI in both HD patients and HDF patients. It demonstrated higher sensitivity for screening patients with mild CI than MMSE. $\mathrm{CI}$ is often under-diagnosed due to the patients' unawareness of their cognitive deficits. Therefore, screening tests would be more appropriate for these patients. The MoCA test which is sensitive to executive dysfunction seems to be more adaptable to assess CI in both groups of this study; HD patients and HDF patients; HDF is a modality of dialysis with better outcome on cognitive function in ESRD patients.

\section{REFERENCES}

Abdel Rahman TT and El Gaafary MM. Montreal Cognitive Assessment Arabic version: Reliability and validity prevalence of mild cognitive impairment among elderly attending geriatric clubs in Cairo. Geriatr Gerontol Int. 2009; 9(1):54-61.

Canaud B, Vienken J, Ash S, et al. Hemodiafiltration to Address Unmet Medical Needs ESKD Patients. CJASN. 2018; 13(9): 1435-1443.

Cobo G, Lindholm B, Stenvinkel P. Chronic inflammation in end-stage renal disease and dialysis. Nephrol Dial Transplant. 2018; 33:(suppl_3):iii35-iii40.

Costa AS, Tiffin-Richards FE, Holschbach B, et al. Clinical predictors of individual cognitive fluctuations in patients undergoing hemodialysis. Am J Kidney Dis. 2014; 64:434-442.

Den Hoedt CH, Bots ML, Grooteman MP, et al., Online hemodiafiltration reduces systemic inflammation compared to low-flux hemodialysis. Kidney Int. 2014; 86(2):423-32. 
El-Okl MA, El Banouby MH and El Etrebi A (2002): Prevalence of Alzheimer dementia and other causes of dementia in Egyptian elderly. MD Thesis, Faculty of Medicine, Ain Shams University.

Folstein MF, Folstein SE and McHugh PR. "Mini-mental state". A practical method for grading the cognitive state of patients for the clinician". Journal of Psychiatric Research. 1975; 12(3):189-198.

Heneka MT, Carson MJ, El Khoury J et al., Neuroinflammation in Alzheimer's disease. Lancet Neurol. 2015; 14(4):388-405.

Iyasere O, Okai D, Brown E. Cognitive function and advanced kidney disease: longitudinal trends and impact on decision-making. Clin Kidney J. 2017; 10(1):89-94.

Kim YS. Effects of HDF on cerebral perfusion and cognitive functioning. Journal of Hypertension. 2018; 36: p e299.

Kurella Tamura M, Larive B, Unruh ML, et al., Prevalence and correlates of cognitive impairment in hemodialysis patients: the Frequent Hemodialysis Network trials. Clin J Am Soc Nephrol. 2010; 5:1429-1438.

Lebourg L, Amato S, Toledano D, et al., Online hemodiafiltration: is it really more expensive? Nephrol Ther. 2013; 9(4):209-14.

Lee SH, Cho A, Min YK, et al., Comparison of the montreal cognitive assessment and the mini-mental state examination as screening tests in hemodialysis patients without symptoms. Ren Fail. 2018; 40(1):323-330.

Morikawa H, Ohashi N, Kawaguchi K, et al., Potential therapeutic system for alzheimer's disease by removal of blood ab: efficient ab removal system by enhancing adsorption on hollow fibers with hemodiafiltration. Alzheimer's \& dementia: the journal of the Alzheimer's Association. 2016; 12(7): P623.

Murray AM, Pederson SL, Tupper DE, et al., Acute variation in cognitive function in hemodialysis patients: a cohort study with repeated measures. Am J Kidney Dis. 2007; 50(2):270-8. 
Nasreddine ZS, Phillips NA, Bédirian V et al., The Montreal Cognitive Assessment, MoCA: a brief screening tool for mild cognitive impairment. $J \mathrm{Am}$ Geriatr Soc. 2005; 53(4):695-9.

Wolfgram DF. Filtering the Evidence: Is There a Cognitive Cost of Hemodialysis? $J$ Am Soc Nephrol. 2018, 29(4):1087-1089.

Zhang YH, Yang ZK, Wang JW, et al., Cognitive Changes in Peritoneal Dialysis Patients: A Multicenter Prospective Cohort Study. Am J Kidney Dis. 2018; 72(5):691700. 